Revista de la red interuniversitaria de estudios sobre las literaturas rioplatenses contemporáneas en Francia

16 | 2017

Esnobismos

\title{
Mansilla y Darío entre postales : ¿celebridad o esnobismo?
}

Inés de Mendonça

\section{OpenEdition}

\section{Journals}

Electronic version

URL: http://journals.openedition.org/lirico/3678

DOI: $10.4000 /$ lirico.3678

ISSN: 2262-8339

\section{Publisher}

Réseau interuniversitaire d'étude des littératures contemporaines du Río de la Plata

\section{Electronic reference}

Inés de Mendonça, "Mansilla y Darío entre postales : ¿celebridad o esnobismo ? ", Cuadernos LIRICO [En línea], 16 | 2017, Puesto en línea el 02 octubre 2017, consultado el 20 abril 2019. URL : http:// journals.openedition.org/lirico/3678; DOI : 10.4000/lirico.3678

This text was automatically generated on 20 April 2019

\section{(c)}

Cuadernos LIRICO está distribuido bajo una Licencia Creative Commons Atribución-NoComercialSinDerivar 4.0 Internacional. 


\title{
Mansilla y Darío entre postales : ¿celebridad o esnobismo?
}

\author{
Inés de Mendonça
}

\author{
Ahora consideremos cuán difícil es, incluso para \\ los grandes hombres, escapar de ser snobs. \\ William Thackeray, El libro de los snobs.
}

1 En marzo de 1903, Rubén Darío escribe en París un texto sobre la tarjeta postal que envía, para su habitual colaboración, al diario La Nación de Buenos Aires, donde es publicado poco después. Unos meses más tarde, en ocasión de una visita a la ciudad porteña, el por entonces consagrado Lucio V. Mansilla, aparece fotografiado en el magazine Caras $y$ Caretas $"$ contestando tarjetas postales ${ }^{1}$, tal como se lee en la bajada de la imagen, inclinado sobre un escritorio, vestido con robe de chambre y pantuflas, y la pluma en la mano. Ambos escritores se quejan de la nueva práctica, calificada como una manía esnob, una moda y una pérdida de tiempo ; sin embargo, no dejan de someterse a ella. Ambos viajan y escriben para la prensa y, aunque el adjetivo cronista no haya sido utilizado con frecuencia para Mansilla, bien podría considerárselo. Sobre todo: ambos poseen una firma legitimante que les otorga celebridad y les garantiza un espacio privilegiado en la prensa periódica.

El mundo del que son contemporáneos el joven Darío y un maduro Mansilla sabe de modas y de públicos lectores cada vez más masivos. La red de conexiones entre los escritores modernistas iberoamericanos configuró un trayecto de intercambios que renovó de un modo profundo tanto poéticas y estéticas como formas de intervención intelectual. Y aunque esos vínculos de amistad profesional -más horizontales- hayan sido imprescindibles, la consolidación de un nuevo campo o de nuevas formas de la esfera pública depende de aportes, cruces y tensiones entre figuras tanto emergentes como residuales. Por aquellos primeros años del siglo conviven (¿y compiten?) aún distintas figuras de autor, que incluyen al más tradicional letrado cosmopolita, los nuevos escritores viajeros profesionales, los poetas-cronistas y los escritores periodistas.

3 Más allá de la orientación general - liberal y cosmopolita- de otros letrados argentinos del ochenta hacia el fomento de las artes, Lucio V. Mansilla comprendió que su propia 
relevancia dependía de esos cruces y se orientó progresivamente hacia los jóvenes. A ellos les dedicó varias de sus últimas causeries en el diario Sud-América y fue entusiasta con un variado y diverso grupo de artistas, trascendiendo incluso ciertas fronteras estamentales. Como ejemplo escueto, mencionemos el apoyo que dio con su ratificación a la beca que Wilde había otorgado a Schiafino en $1884^{2}$, o su elogio al tono irreverente y vernáculo de José S. Álvarez (Fray Mocho), a quien mencionó como el único que, además de él mismo, escribía en verdadero tono argentino ${ }^{3}$.

Desde esta posición de autoridad que, aunque reconocida, sobre todo es sostenida por la propia escritura de Mansilla sobre sí, recibió con hospitalidad al joven Darío cuando éste llegó a Buenos Aires. Colaboró en abrirle las puertas del ambiente literario y de la prensa de Buenos Aires y le otorgó su aprobación -además de dedicarle un artículo y un banquete en su honor, tal como lo apunta el poeta en su "Autobiografía »-. Darío retribuyó favores suscribiendo en varios textos todas las características que eran, para entonces, la impronta aceptada de la figura de autor del general : la mitificación de su belleza, su don de gentes, su extravagancia y su locuacidad ${ }^{4}$.

Así relata Darío su primer encuentro con Mansilla :

En la redacción de Tribuna me relacioné, por presentación de Mariano de Vedia, con el doctor Lorenzo Anadón, con el general Mansilla, y los poetas Carlos Roxlo y Christián Roeber. Mansilla simpatizó mucho conmigo y publicó a este respecto un precioso y chispeante artículo. Le visité. En su casa me mostró cosas curiosísimas, entre ellas el mejor retrato que yo haya visto de su tío D. Juan Manuel de Rozas. Alcancé a conocer también a su madre, doña Agustina, la belleza célebre que aun resplandecía en su ancianidad, y a quien, cuando murió, deshojé un ramillete de rosas literarias ${ }^{5}$.

6 La fotografía de Mansilla que mencionamos al comienzo figura en uno de los distintivos « reportajes ilustrados » que solía publicar Caras y Caretas, en el que se consulta al general como una voz autorizada para hablar sobre la coyuntura política y cultural del país, pero sobre todo como personalidad pública llamativa, con la relevancia de una celebridad social a la que vale la pena retratar. « Permítanos usted fotografiarle -escribe un anónimo repórter-, Buenos Aires viviría desconsolado si gráficamente no guarda el secreto de sus poses ${ }^{6}$. La figura de autor que ha construido se sustenta en ciertos gestos públicos retratados en la prensa en los que aflora un personaje que se ratifica con el esmerado cuidado de una imagen distintiva. En el diálogo con el entrevistador, Mansilla se queja por la interminable tarea de firmar y contestar postales, a las que contabiliza, con su habitual grandilocuencia, en más de tres mil. El repórter acota :

La ilustre víctima de la manía de moda no nos pareció ya tan alegre. Tenía los ojos llenos de reproches, como cualquier mortal acosado por el snobismo de esta plaga devastadora que a nadie da reposo en el mundo contemporáneo ${ }^{7}$.

7 En el artículo que escribía Darío, apenas unos meses antes, también aparece la queja ante la nueva costumbre y el tiempo que insume: «La verdad es que la moda de la tarjeta postal ilustrada, o artística, aumenta cada día más $»^{8}$. Pero aunque lo critica, también acepta ser parte del fenómeno :

¿Podré decir que me he visto libre de las innumerables ofertas? No. He comprado en Nápoles y en Londres, en un rincón de Sorrento, en Capri, en Pompeya [...]".

8 Las postales han venido a reemplazar la anterior costumbre del intercambio epistolar, dice Darío, por tornarse imposible contar con el tiempo para escribir cartas, en « la vida actual, sobre todo, esta vida europea y en particular la de París ». Y, aunque se lamente por la pérdida, acepta el beneficio de la nueva manía : «Si antes se recibía una carta, hoy 
se reciben cincuenta tarjetas postales $»^{10}$. Lamento y fascinación conviven en la mirada que el cronista ofrece sobre la nueva práctica. La melancolía parece ceder ante la curiosidad y el beneficio de la velocidad.

Para el autor, si la tarjeta postal ordinaria ya había reducido el intercambio verbal a unas pocas frases, la tarjeta postal ilustrada reemplaza a ambas, « en la cual no se pone nada $»^{11}$ . Esa forma del vacío que, sin embargo, está plagado de significados, con imágenes variopintas de paisajes, monumentos, personas y personajes, manifiesta uno de los riesgos que el poeta-cronista parece avizorar en algunas prácticas culturales que tienden a masificarse. Como plantea Graciela Montaldo en su ensayo sobre las crónicas darianas :

Darío ensaya su mirada hacia la cultura popular y masiva en diferentes grados ; [...] mira con sorna la costumbre de enviar tarjetas postales pero a la vez la considera una práctica integrada a la difusión de la estética en la vida cotidiana ${ }^{12}$.

10 Su crónica comenta a los lectores que en cualquier punto donde se detengan las caravanas de turistas, podrán encontrarse «los puestos y tiendas de tarjetas [...] de la ciudad o pueblo, desde la recóndita China hasta la clara Italia, desde las pirámides hasta el país del Sol de medianoche $»^{13}$. A diferencia de sus predecesoras las cartes de visite, las tarjetas postales ilustradas dan cuenta de una práctica viajera más extendida, menos elitista y más esnob. Si las cartas de visita transformaban el cuerpo retratado de su propietario en un objeto de intercambio, que atestiguaba un cierto recorrido y una sociabilidad restringida, la postal ilustrada corre del centro de la imagen a su emisor para convertirse en un vestigio -a su modo una reliquia- de una experiencia que no por ser comerciable deja de vivirse como subjetiva. Se trata, entonces, de una tímida democratización del lujo a la que ambos se pliegan también como consumidores.

11 La firma autógrafa que le solicitan sus lectores (en particular las lectoras) tanto a Mansilla como a Darío vuelve a la postal ilustrada una suerte de relicario que contiene la huella material quirográfica junto al halo legitimante de su fama. Si firmar inaugura para el que deja su marca (sea o no letrado, ya que hay firmas de personas ágrafas) la posibilidad de acceder « al poder de lo inscripto » y, por ende, de constituirse en un sujeto jurídico que tiene derechos escritos sobre los que puede reclamar -tal como señala Béatrice Fraenkel ${ }^{14}$ - entonces la noción de firma puede acercarse a la de autoría.

Las postales autografiadas generan un circuito de intercambio entre autor y lectores, donde lo que se valora es la firma emancipada de los textos que le otorgaron renombre. Comúnmente atesoradas en álbumes, las postales firmadas acercan la experiencia del autor-productor a la del lector-consumidor y hacen propio un capital (simbólico) ajeno. Desde sus cualidades letradas (de práctica de la escritura, identidad y propiedad), el yo que firma puede otorgar el don de la dedicatoria. Mansilla había practicado con fruición el don de las dedicatorias en sus textos públicos pero esta nueva práctica privada, de vínculo directo con los lectores anónimos, abre el circuito del entre-nos al de las formas mediatizadas de la nueva industria cultural. El gesto escrito remeda, sin embargo, cercanías amistosas e incluso físicas y confiere al texto dedicado un poder que liga imaginariamente al autor (su nombre, su firma, su persona) al dedicatario. Esos pequeños fragmentos de escritura y la carga aurática del autógrafo otorgan al objeto un valor coleccionable. El nombre que firma carga con la reputación acumulada y la letra del autor con una densidad simbólica y referencial.

Escribe Darío :

me hacen el honor de enviarme sendas tarjetas que solicitan un autógrafo. De todas clases han llegado: con figuras de niños entre flores, con vistas y pasajes, con 
retratos de reinas y cortesanas famosas, con sencillas viñetas, y con complicados dibujos. He atendido gustoso las solicitudes $[. . .]^{15}$. vida del autor para insertarse en la vida del lector. Las tarjetas se acumulan e intercambian. Se atesoran como marcas de prestigio pero circulan masivamente como souvenirs, en tanto, como sugiere Adriana Amante «objeto que recuerda un lugar por donde se ha pasado y del que se conserva un fragmento $»^{16}$. La calidad objetual, que Amante retoma de la lectura de Susan Stewart ${ }^{17}$, implica la reducción del espacio transitado a una dimensión portable. En palabras de Darío: «es la ilusión de la presencia $»^{18}$ que puede llevarse de un sitio a otro, confirmando la experiencia turística o, en este caso, el contacto con el autor venerado.

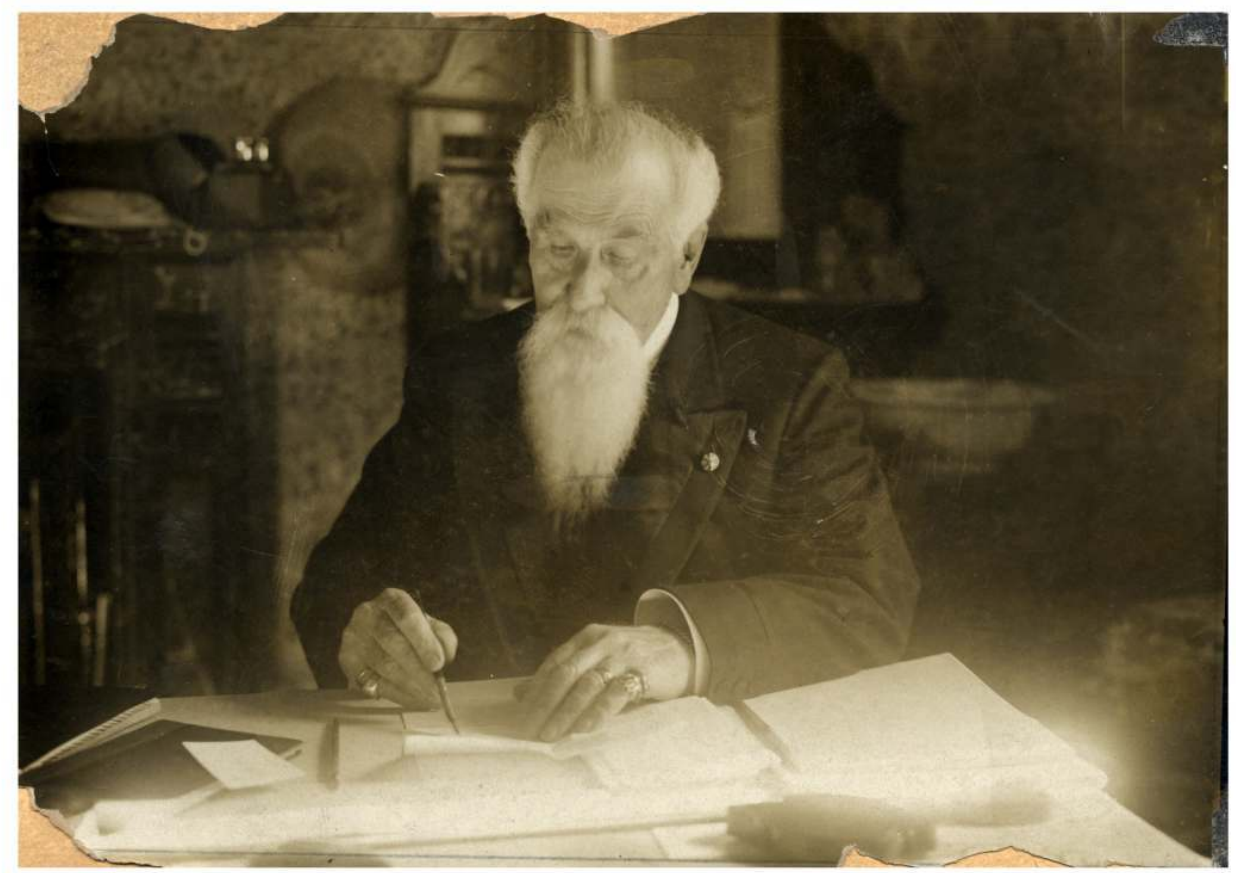

Mansilla escribiendo con su larga pera blanca (circa 1903), Departamento de documentos fotográficos, Archivo General de la Nación.

La imagen y la firma sostienen, entonces, la ilusión de una presencia anhelada y atesorable. Tanto Mansilla como Darío se ofrecen como marcas culturales coleccionables. El encuentro con ese otro, en tanto celebridad, mientras genere relato, también puede considerarse una forma biográfica cercana al souvenir.

Ahora bien, ambos autores definen en algún punto a la tarjeta postal como marca de esnobismo. Y consideran lo esnob como una forma degradada, menor o falaz, de lo cultural. La aparición del término y la oscilación en la apreciación del fenómeno, que no deja de incluirlos, permite leer tal vez un pasaje, un cambio que, en formas iniciales de la industria cultural, ubica a los autores como objetos de atención en tanto figuras, me permito decir anacrónicamente, performers de su propia obra. ¿No será esta pose, este modo de la celebridad, una forma también del criticado esnobismo ?

Uso, abuso y moda son las tres palabras que utiliza Darío para definir la práctica de recibir y mandar tarjetas postales. Si tanto Mansilla como Darío asumen el valor negativo de lo esnob como el deseo de aparentar o la insistencia en gestos vacíos de admiración a todo lo 
que "debe hacerse", la pregunta que resuena es ¿cuál es el límite por el cual una forma, una práctica o un objeto cultural constituyen distinción o se diluyen en una indiferenciada masividad? ¿Cuáles son las implicancias de esta diferencia para las formas literarias del entresiglo? De las escrituras y prácticas de estos firmantes de postales, podríamos pensar que es por el modo en que cada sujeto se apropia de la moda que pueden diferenciarse el buen dandi del advenedizo esnob. Porque no es lo mismo estar a la moda que estar de moda, aunque, como en el caso de las postales, el límite entre participante y observador tiende a difuminarse.

El año en que se publica el reportaje ilustrado que mencionamos al comienzo, Lucio V. Mansilla tiene setenta y dos años y vive en París, junto a su segunda esposa, en la que sería su última residencia. Sus viajes de ida y vuelta entre Europa y Buenos Aires atraen la atención de la prensa. Su rostro, sus poses, su vestimenta son para ese momento, objeto aceptado de admiración y, también, de sorna ${ }^{19}$. Esta puesta en foco de su corporalidad es un efecto directo de la apuesta literaria y textual que lleva adelante desde sus primeros escritos y que continúa con perseverancia hasta el final de sus días. El culto a la belleza propia y heredada- junto a la seducción de su fluida locuacidad, que el causeur se ha ocupado de cimentar, lo rodean aún en la madurez. Así lo describe Darío en una de sus crónicas parisinas, al encontrárselo paseando por el Louvre :

Luego noto la presencia de una figura conocida. El fieltro con el ala doblada verticalmente, la tez de buen color sonrosado, los ojos vivos, la larga pera blanca que cae sobre el pecho erguido, todo el aspecto con algo de militar, de mundano y de artista. A poco estoy hablando con el personaje. Es el general Mansilla. Y como se acercan los doctores hispanoamericanos Debayle y Amoedo, todos escuchamos al admirable conversador, que habla largamente.

Dos autoridades en la materia, Maurice Barrès y Robert de Montesquiou, han alabado como se debe el don de la palabra florida, oportuno y espiritual en este argentino, que es una de las personalidades más parisienses.

[...]

Lleno de años, conserva su famosa elegancia masculina. No se refugia en el encierro como un Sagán. Pasea, goza del aire libre de que siempre gustaron su alma libre y su cuerpo sano. Y aun parece que en la galantería misma, listo estaría el mismo Eros para decirle : « Presente, mi general !»

[...]

Y nos separamos de él alabándole y deseando para nosotros una vejez, no verde, sino como ésa, dorada y de color de rosa ${ }^{20}$.

Por la conciencia de los medios en que sostiene su práctica, Alan Pauls considera a Mansilla un dandi ${ }^{21}$. En su lectura, la pose y el uso del propio cuerpo como objeto, su estetización y su mostración, son simultáneamente base y efecto del artificio dandi. Podríamos cuestionar, como lo ha hecho Silvia Molloy ${ }^{22}$, si la marginalidad y rebeldía de la actitud dandi puede asumirse por entera para el complejo personaje que construye el causeur (siempre intentando ocupar posiciones de poder a las que no llega, siempre algo desfasado o desubicado en sus colocaciones sociales) ; pero, por cierto, la impostura del lujo y el esfuerzo -velado- por componer un personaje nos permiten manejar la categoría, aun con reparos, para pensar en los retratos visuales y verbales que evocan su figura como la de un atildado diletante. Alguien que se exhibe por puro gusto y para ofrecerse a los demás.

Se trata de ese contorno que delinea Darío al observarlo en los pasillos del Louvre: artista, elegante y mundano. El cuidado personal y la afectación, como un ademán indiscutido al que el nicaragüense, como otros, rinde reverencia en su semblanza. 
21 para definir al diletantismo del dandi. Es más bien una actidud y una sensibilidad. Para Edgardo Cozarinsky, sin embargo, «la elegancia como invisibilidad de la apariencia $~^{24}$ constituye una de las formas posibles del dandismo. Entre la refinada sutileza y la máxima exhibición, el problema que se pone en juego es la distinción como frontera práctica de la diferencia social.

Un desparpajo (en ocasiones parco, en ocasiones exuberante, en ocasiones ridículo) que produce diferencia. Y tal vez sea la relación tirante y contradictoria entre distinción y popularidad, la que nos lleva a pensar en Mansilla y Darío como figuras oscilantes: refractarias, pero también tentadas hacia formas de lo esnob, como derivación multiplicada de lo dandi.

"¿Cómo sería una historia del esnobismo en el mundo hispánico, una historia sin Cambridge, sin Thackarey, e incluso -en gran medida- sin la palabra 'snob'?», se pregunta Víctor Goldgel al trazar una aproximación a los modos propios que la paquetería, el dandismo y también su contraparte menos prestigiosa, el rastacuerismo, asumen en la América hispana en el siglo XIX ${ }^{25}$. Propone una terminología vernácula para referirnos a las figuras en cuestión : lo cursi y lo cajetilla, dos formas de la afectación que permean la literatura hispanoamericana desde, al menos, mitad del siglo XIX y que pueden servirnos para pensar en las formas específicas de sociabilidad y escritura que leemos.

Es interesante volver a leer cómo adjetiva Darío al anciano Mansilla en el Louvre : un argentino con la personalidad "más parisiense ». ¿Para qué lectores escribe Darío estas «Opiniones »? ¿De qué se aleja y dónde pretende ubicarse Darío ? ¿No está cayendo en la actitud esnob, y hasta cursi, de ponderar lo europeo de un escritor americano ? Beatriz Colombi enumera los términos que toma la simulación cultural en las crónicas parisinas de Darío hacia el novecientos : bárbaro, extranjero, parvenu, y rastacueros, «formas que tiene el discurso del etnocentrismo para caratular al otro $»^{26}$ y señala que, al recorrer la Exposición Universal, Darío es sensible a las situaciones de colonialismo aún vigentes pero que también ocupa, con melancolía, la posición del intelectual viajero que quiere obtener reconocimiento y diferenciarse de los advenedizos que ostentan desde la apariencia y el gasto. El deseo por lograr un lugar destacado para los escritores hispanoamericanos en París había sido tema de la polémica que Darío sostuvo con Unamuno, unos años antes, en 1899. En ese sentido, el afrancesamiento de la personalidad argentina es significativo como aspiración de integración.

Cuando en un artículo de 1906 escribe que «el rastacuerismo tiene como condición esencial la incultura; o mejor dicho, la carencia de buen gusto $»^{27}$, define una lógica de diferenciación que ya no depende del acceso económico, o de la proveniencia geográfica, sino de la posesión (o no) de ciertas competencias. Esta forma de selección negativa que intenta separar a los buenos de los malos consumidores culturales, a los que merecen y no merecen ingresar en un circuito y una sociabilidad, nos recuerda que también Mansilla y Darío son visitantes hispanoamericanos en el centro cultural que es París hacia el novecientos. Este texto discute y amplía, de algún modo, las crónicas sobre la Feria de Paris escritas para La Nación seis años antes. Al expandir el uso del término cuestiona la noción centro-periferia implícita en su significación léxica. Colombi recuerda que esta cuestión aparecerá luego en el Canto Errante, cuando el poeta diga que « en París, 'ombligo de la locura', hace buenamente su papel de sauvage $»^{28}$. 

ampliación de públicos como el rizo inesperado que va de la distinción elitista de los escritores en París a la lectura de la prensa periódica en los bares o las esquinas de la ciudad americana moderna. Aunque incómodos frente al fenómeno, Mansilla y Darío intuyeron la creciente disolución entre cultura alta y baja. Cuestionaron con su práctica (aunque no siempre en su discursividad explícita) la separación entre formas aristocratizantes y populares. En esta bisagra la lengua se presenta como clave: trasciende y exporta modelos, permea fronteras, se disuelve y reaparece en asociaciones nuevas. Como fervorosos renovadores del español americano, desde el coloquialismo exquisito de Mansilla -a la vez pampeano y francés- o desde las búsquedas formales y léxicas modernistas - del poeta y también del diarista- adoptaron cómodamente la posición de quien distribuye legitimidades y diseña nuevos gustos ${ }^{31}$. Pero junto a esa distinción, crearon nuevos públicos y expandieron el consumo de objetos culturales. Desde el elitismo de la forma y cierta resistencia al poder, la búsqueda de originalidad en la vida y en la obra, se ofrecieron como espectáculo para los lectores.

\section{Una coda : multiplicarse}

En la única copia de la serie de multifotografías que se encuentra disponible a consulta en las que Mansilla juega a multiplicarse de frente y de espaldas- en el Archivo General de la Nación argentino, se puede leer escrito a mano en el dorso: "El simpático General Lucio V. Mansilla en una pose fotográfica muy de moda en aquellos tiempos ». Esa técnica que podía pasar por vanguardista y elitista era sin embargo una simple y comercial propuesta de los estudios. En 1895 ya aparecían chistes respecto del truco en un periódico en Filadelfia, aduciendo que la técnica podría habérsele ocurrido a cualquier « viajero de ascensor ». Siguió usándose hasta la década del '30 del siglo XX pero para ese momento se lo consideraba un procedimiento comercial de poco valor artístico por su simpleza ${ }^{32}$. Sin embargo, algunos experimentos que llevarán adelante, entre otros, los surrealistas cuestionan esta asociación entre simpleza y valor estético negativo para las fotos con juego de espejos. 
Darío se repetiría, más allá de sí mismo, replicado en los tangos y en los barrios. Podemos pensar que su ¿sorpresiva? popularidad lo convirtió en un poeta plebeyo (como lo llama despectivamente Evar Méndez). Un poeta que fue hacia las muchedumbres, aun con la contradicción de haberse tentado por la torre de marfil. Las vecinas de barrio y los niños de escuela pública aprenden sus versos de memoria y los poetas tangueros adquieren cierto manierismo modernista que pasa de los interiores palaciegos al terciopelo malandrín. Porque, como nos enseña a mirar Silvia Molloy ${ }^{33}$, en la pose modernista, cosmopolitismo y modernidad son sinónimos. La celebridad de estos escritores hacia el fin de siglo XIX, su trabajo con la lengua, su circulación, y sus posturas ambivalentes de cercanía y rechazo a los lectores y al acceso al consumo cultural, manifiestan formas novedosas en la relación centro-periferia e inauguran formas híbridas de la figuración cultural.

\section{BIBLIOGRAPHY}

AMANTE, Adriana. Poéticas y políticas del destierro. Argentinos en Brasil en la época de Rosas. Buenos Aires : Fondo de Cultura Económica, 2010.

COLOMBI, Beatriz. “Peregrinaciones parisinas : Rubén Darío”, Orbis Tertius, 2 (4), 117-130. En Memoria Académica, 1997. Disponible en : http://www.fuentesmemoria.fahce.unlp.edu.ar/ art_revistas/pr.2678/pr.2678.pdf, consultada el 1/8/2017.

COZARINSKY, Edgardo. "Prólogo", en HAZLITT, THACKERAY, WILDE, WOOLF. Gentlemen. Los mejores escritos del dandismo inglés. Buenos Aires : Mardulce, 2015.

DARÍO, Rubén. « En el Louvre », Todo al vuelo. Obras Completas. Volumen XVIII, Madrid : Editorial Mundo Latino, 1912, p. 26-28. « La evolución del rastacuerismo », Opiniones. Obras Completas, Volumen X, Madrid : Editorial Mundo Latino, 1906. Viajes de un cosmopolita extremo, (Selección y prólogo de Graciela MONTALDO), Buenos Aires : Fondo de Cultura Econónima, 2013. Autobiografía. Obras Completas. Volumen XV, Madrid : Editorial Mundo Latino, 1913.

FRAENKEL, Béatrice. "La firma contra la corrupción de lo escrito" en Jean BÓTTERO y otros. Cultura, pensamiento, escritura. Barcelona : Gedisa, 1995.

GARCÍA MORALES, Alfonso. « Un lugar para el arte. Rubén Darío y Eduardo Schiaffino (documentos y cartas inéditas) ", Anales de Literatura Hispanoamericana, vol. 33, 2004, p. 109. Disponible en : http://revistas.ucm.es/index.php/ALHI/article/view/ALHI0404110101A/21970, consultada el 4/1/2017.

GOLDGEL, Víctor. « Entre dandis y rastacueros. Aproximaciones al esnobismo del siglo XIX latinoamericano ", Estudios de Teoría Literaria, Revista digital, Año 3, Nro. 5, 2014, Facultad de Humanidades / UNMDP, ISSN 2313-9676, disponible en <http://fh.mdp.edu.ar/revistas/ index.php/etl/article/view/852/871>, consultada el 2/5/2016. 
MANSILLA, Lucio V. Entre-Nos. Causeries del jueves. Buenos Aires : Hachette. 1963.

MENDONÇA, Inés de. “Y ese coronel Mansilla, ¿quién es ?”, en Hernán BISCAYART (comp.). Lecturas de travesía. Literatura Latinoamericana. Buenos Aires : NJ Editor, 2012.

MOLLOY, Silvia. "Imagen de Mansilla", en Gustavo FERRARI y Ezequiel GALLO [comp.], La Argentina del ochenta al centenario. Buenos Aires : Sudamericana, 1980.

Silvia. Poses de fin de siglo. Desbordes del género en la modernidad. Buenos

Aires : Eterna Cadencia, 2012.

MONTALDO, Graciela. « Guía Rubén Darío » en Rubén DARÍO. Viajes de un cosmopolita extremo. Buenos Aires : Fondo de Cultura Econónima. 2013, p. 42.

PAULS, Alan. « Fuego artificial », prólogo a BALZAC, Honoré de ; BAUDELAIRE, Charles y BARBEY D'AUREVILLY, J.A. El gran libro del dansimo. Buenos Aires : Mardulce, 2013.

REICHSTEIN, Irwin. « A Multigraph from Montreal », Photographic Canadiana, 33-1, mayo/junio de 2007.

ROMAN, Claudia. Prensa, política y cultura visual. El Mosquito (1863-1893). Buenos Aires : Ampersand, 2017.

[S.N.] « Reportaje al General Mansilla. Artículo de Don Lucio », Buenos Aires : Caras y Caretas, número 267, 14 de noviembre de 1903.

STEWART, Susan. On Longing: Narratives of the Miniature, the Gigantic, the Souvenir, the Collection, Durham. NC : Duke University Press, 2003.

VIÑAS, David. Literatura Argentina y Realidad Política. La crisis de la ciudad liberal. Buenos Aires : Ediciones Siglo Veinte, 1973.

\section{NOTES}

1. [S.N.]. «Reportaje al General Mansilla. Artículo de Don Lucio», Buenos Aires: Caras y Caretas, número 267, 14 de noviembre de 1903.

2. Alfonso García Morales. «Un lugar para el arte. Rubén Darío y Eduardo Schiaffino (documentos y cartas inéditas)», Anales de Literatura Hispanoamericana, vol. 33, 2004, p. 109. Disponible en: <http://revistas.ucm.es/index.php/ALHI/article/view/ ALHI0404110101A/21970>

3. Lucio V. Mansilla, «Académicos de número, honorarios, correspondientes y electos». Entre-Nos. Causeries del jueves, Buenos Aires: Hachette. 1963, p. 486.

4. Sobre la construcción de la imagen escrita y fotografiada de Mansilla he trabajado en un artículo anterior: Inés de Mendonça, “Y ese coronel Mansilla, ¿quién es?”, en Hernán Biscayart (comp.), Lecturas de travesía. Literatura Latinoamericana, Buenos Aires: NJ Editor, 2012.

5. Rubén Darío, Autobiografía, Obras completas, Volumen XV, Madrid: Editorial Mundo Latino, 1913, p. 146.

6. [S.N.] ibidem.

7. [S.N.] ibidem.

8. Rubén Darío, «La tarjeta postal», Viajes de un cosmopolita extremo, selección y prólogo de Graciela Montaldo, Buenos Aires: Fondo de Cultura Económica, 2013, p. 332.

9. Rubén Darío, Ibidem, p. 335. 
10. Rubén Darío, Ibidem, p. 333.

11. Ibidem, p. 337.

12. Graciela Montaldo, «Guía Rubén Darío» en Rubén Darío, Viajes de un cosmopolita extremo, Buenos Aires: Fondo de Cultura Económica. 2013, p. 42.

13. Ibidem, p. 332.

14. Béatrice Fraenkel, "La firma contra la corrupción de lo escrito" en Jean Bóttero y otros. Cultura, pensamiento, escritura, Barcelona: Gedisa, 1995.

15. Rubén Darío, Ibidem.

16. Adriana Amante, Poéticas y politicas del destierro. Argentinos en Brasil en la época de Rosas, Buenos Aires: Fondo de Cultura Económica, 2010, p. 563.

17. Susan Stewart, On Longing: Narratives of the Miniature, the Gigantic, the Souvenir, the Collection, Durham, NC: Duke University Press, 2003.

18. Rubén Darío, 2014, p. 337.

19. Desde la muerte de Sarmiento, Mansilla figuraba en la publicación jocosa «El Mosquito», como parte de la "M" en la viñeta de portada. Hacia 1903, su perfil tipificado y caricaturizado era presencia habitual y lugar común para la prensa porteña y su circuito letrado. Para leer sobre modos de funcionamiento de la prensa satírica, ver: Claudia Roman, Prensa, política y cultura visual. El Mosquito (1863-1893), Buenos Aires: Ampersand, 2017.

20. Rubén Darío, «En el Louvre», Todo al vuelo. Obras Completas. Volumen XVIII, Madrid: Editorial Mundo Latino, 1912, p. 26-28.

21. Alan Pauls, «Fuego artificial», prólogo a Balzac, Baudelaire y Barbey d'Aurevillu, El gran libro del dansimo, Buenos Aires: Mardulce, 2013.

22. Silvia Molloy señala la diferencia entre el discurso intransigente del dandi -tal como lo pinta Baudelaire- y el discurso de Mansilla, que busca insistentemente complacer a otro (lector o mecenas). Silvia Molloy, "Imagen de Mansilla" en Gustavo Ferrari y Ezequiel Gallo (comps.), La Argentina del ochenta al centenario, Buenos Aires: Sudamericana, 1980. En una orientación similar, la categoría de gentleman que utiliza David Viñas para Mansilla presupone una colocación de clase nodal para su textualidad que impediría considerar su actitud como dandismo. David Viñas, Literatura Argentina y Realidad Política. La crisis de la ciudad liberal, Buenos Aires: Ediciones Siglo Veinte, 1973.

23. Alan Pauls, Ibidem, p. 15.

24. Edgardo Cozarinsky, "Prólogo”, en Hazlitt, Thackeray, Wilde, Woolf, Gentlemen. Los mejores escritos del dandismo inglés, Buenos Aires: Mardulce, 2015, p. 12.

25. Víctor Goldgel, «Entre dandis y rastacueros. Aproximaciones al esnobismo del siglo XIX latinoamericano», Estudios de Teoría Literaria, Revista digital, Año 3, Nro. 5, 2014, Facultad de Humanidades / UNMDP, ISSN 2313-9676, disponible en <http:// fh.mdp.edu.ar/revistas/index.php/etl/article/view/852/871>, consultada el 2/1/2016.

26. Beatriz Colombi, "Peregrinaciones parisinas: Rubén Darío", Orbis Tertius, 2 (4),

117-130. En Memoria Académica, 1997. Disponible en: http://

www.fuentesmemoria.fahce.unlp.edu.ar/art_revistas/pr.2678/pr.2678.pdf

27. Ruben Darío, «La evolución del rastacuerismo», Opiniones, Obras Completas, Volumen X, Madrid: Editorial Mundo Latino, 1906, p. 126.

28. Colombi, Ibidem, p. 9.

29. Lucio V. Mansilla, «Los siete platos de arroz con leche», Ibidem, p. 92.

30. David Viñas, Ibidem.

31. Un trabajo aparte merecería la posición gloto y geopolítica de ambos respecto de España (en particular por la guerra de Cuba pero en general como entusiastas de cruces y 
lecturas entre Madrid e Hispanoamérica). Un nuevo iberoamericanismo que podía dejar atrás la necesidad de separarse políticamente de la cultura peninsular que habían tenido las generaciones anteriores.

32. Irwin Reichstein, “A Multigraph from Montreal”, Photographic Canadiana, 33-1, mayo/ junio de 2007.

33. Silvia Molloy, Poses de fin de siglo. Desbordes del género en la modernidad, Buenos Aires: Eterna Cadencia, 2012.

\section{ABSTRACTS}

In March 1903, Rubén Dario writes in Paris a text about postcards for his usual collaboration with Argentinian newspaper La Nación, from Buenos Aires. A few months later, while visiting this city, Lucio V. Mansilla appears photographed in the magazine Caras y Caretas "answering postcards". Both complain about the new practice, described as a snobbish mania, a fashion, and a waste of time; however, they submit to it. Both, travelers and chronicle writers, have a legitimizing signature that gives them celebrity. In what position are they in to follow or condemn fashion? What does it mean to be "fashionable"? Is this pose, or their celebrity, a form of the criticized snobbery too? We propose to think about the contradictory relationship between distinction and popularity, and about both authors as oscillating figures: refractory, but also tempted into forms of snobbery, as a multiplied diversion from dandyism.

En marzo de 1903, Rubén Darío escribe en París un texto sobre la tarjeta postal que envía para su habitual colaboración al diario La Nación de Buenos Aires. Unos meses más tarde, en ocasión de una visita a la ciudad porteña, el por entonces consagrado Lucio V. Mansilla aparece fotografiado en el magazine Caras y Caretas "contestando tarjetas postales". Ambos se quejan de la nueva práctica, calificada como una manía esnob, una moda y una pérdida de tiempo ; sin embargo, no dejan de someterse a ella. Ambos, viajeros y cronistas para la prensa, poseen una firma legitimante que les otorga celebridad. ¿En qué lugar se ubican para seguir o condenar la moda? ¿Qué implica en el caso de estos escritores "estar a la moda" ? ¿No será esta pose, este modo de la celebridad, una forma del criticado esnobismo? Proponemos pensar la relación contradictoria entre distinción y popularidad, y a ambos autores como figuras oscilantes : refractarias, pero también tentadas hacia formas de lo esnob,

À Paris, Rubén Darío écrit en mars 1903, pour le journal La Nación de Buenos Aires, un article sur la carte postale. Quelques mois plus tard, le magazine Caras y Caretas publie une photo de Lucio V. Mansilla, déjà consacré, à l'occasion d'une visite à Buenos Aires: il s'attaque à la tâche que suppose le fait de répondre aux cartes postales. Tous les deux se plaignent de la nouvelle habitude, qu'ils considèrent comme un snobisme, une mode et une perte de temps, bien qu'ils s'abandonnent à elle. En tant que voyageurs et chroniqueurs de la presse, leurs signatures sont célèbres, en leur donnant légitimité. Quelle est la raison de leur rejet/acceptation de la mode? Leur exercice de la célébrité ne serai-t-il pas une pose, une forme du snobisme critiqué ? Nous proposons de penser la relation distinction/popularité chez les deux écrivains, ainsi que leurs attitudes de rejet/tentation du snobisme et du dandysme. 
INDEX

Keywords: snobbery, dandyism, postcards, Rubén Darío, Lucio V. Mansilla

Mots-clés: snobisme, dandysme, carte postale, Rubén Darío, Lucio V. Mansilla

Palabras claves: esnobismo, dandismo, postales, Ruben Darío, Lucio V. Mansilla

\section{AUTHOR}

INÉS DE MENDONÇA

UBA-Instituto de Literatura Hispanoamerican (ILH)

inesdm@gmail.com 